\title{
Simulation Study on Heating Performance of a Cabin
}

\author{
Dong-Hyun Cho ${ }^{1}$ \\ ${ }^{1}$ Department of Mechanical Engeering, Daejin University, South Korea \\ chodh@daejin.ac.kr
}

\begin{abstract}
For the first time at home and abroad, this study implemented radiant heating with the thermal energy supplied from hot water by embedding hot water panels in the walls of a single-person cabin and installing hot water tubes inside the hot water panels. The size of the single-person cabin is $2000 \mathrm{~mm}$ wide, $1050 \mathrm{~mm}$ long, and $2200 \mathrm{~mm}$ high. The single-person cabin of the same size as that of a single bed was studied so that the single-person cabin can be used as a bed at normal times, and used for dry sauna by those who like dry sauna in their own house where they live. The results of simulation of the air temperature distribution inside the single-person cabin in this study showed a uniform distribution of air temperature resulting from the radiant heat transfer inside the single-person cabin and the temperature distribution was shown to be a well-being temperature distribution beneficial to health.. In addition, in this study, the air temperature distribution measured in the experimental study and the temperature distribution value shown in the simulation results were in good agreement.
\end{abstract}

Keywords: Cabin, Water panel, Heat transfer, Winter heating device, Temperature distribution

\section{Introduction}

At home and abroad, winter heating devices (hot water boilers, air conditioners, etc.) for existing single-person cabins are mainly supplied to buildings in which they are used for heating areas not smaller than $26 \mathrm{~m}^{2}$, and many studies have been reported on heating technologies for convective heat transfer by air circulation [1][2]. As demand for residence in single-person cabins is gradually increasing, studies on heating device technologies suitable for single-person cabins are desperately required but reports of the results of such studies are currently insufficient. In addition, in the case of heating technologies for single-person cabins of the elderly, reports of studies beneficial to sleep as well as health are desperately required but such reports are still somewhat insufficient. Therefore, based on the results of this study [3][4], it is considered that if single-person cabin beds that can be also used as loess dry sauna rooms are studied and supplied, the health of the elderly can be greatly improved with comfortable and cozy sleep and radiant heat dry sauna in the loess rooms. In addition, since there is no heating device accessories (circulation pump, heater, etc.) suitable for small residential spaces larger than $3.3 \mathrm{~m}^{2}$, accessories used in residential spaces not smaller than $26 \mathrm{~m}^{2}$ are used in buildings not larger than $3.3 \mathrm{~m}^{2}$ leading to great electric power energy losses and drastic increases in installation costs [5]. Therefore, a single-person cabin and a bed with

Article history:

Received (October 9, 2020), Review Result (November 12, 2020), Accepted (December 17, 2020)

JHSTI

Copyright (C) 2021 Global Vision Press (GV Press) 
a heating area of $0.63 \mathrm{~m}^{2}$ that can be also used as a loess dry sauna room was studied to implement well-being heating beneficial to health by supplying radiant heat from hot water by embedding hot water panels in the bed and the walls and configuring the hot water panels so that hot water is circulated in them [6][7][8]. In addition, a loess bed and loess walls verified from various studies and reference materials were constructed so that a residential life with a bed and the loess dry sauna room can be implemented at the same time [9]. The bed and walls were constructed with loess ondol panels to implement loess radiant heat room heating thereby developing a well-being heating technology beneficial to health. In winter, the temperature of the hot water circulating in the ondol panels of the bed and walls can be raised and adjusted so that loess radiant heat dry sauna can be enjoyed in the bed space depending on the resident's taste. In spring and autumn, the ceiling of the single-person cabin with bed that can be also used as a loess dry sauna room can be placed at the height of the ceiling of the room, the wall can be placed in close contact with the wall of the room, and the door can be opened or easily detached depending on the resident's taste so that the singleperson cabin has the same feeling and sense as a normal bed and can be used as a bed. Depending on the resident's taste, even in spring and autumn, the door can be closed, and the loess radiant heat dry sauna room can be operated whenever the resident wants to enjoy loess radiant heat dry sauna. In addition, the existing heating of a single-person cabin heated the entire room (10 to $13 \mathrm{~m}^{2}$ ), but in this study, a technology that can only heat the bed space $\left(0.63 \mathrm{~m}^{2}\right)$ was developed to greatly reduce the heating energy consumption rate.

\section{Experimental apparatus and method}

Figure 1 shows a 3D schematic diagram of the single-person cabin experimental apparatus in which the thermal energy held by hot water circulating in the hot water panels embedded in the walls of the single-person cabin is supplied to the air inside the single-person cabin for heating. As shown in [Figure 1], for the first time at home and abroad, this study examined radiant heating with the thermal energy supplied from hot water by embedding hot water panels in the walls of a single-person cabin and installing hot water tubes inside the hot water panels. The size of the single-person cabin is $2000 \mathrm{~mm}$ wide, $1050 \mathrm{~mm}$ long, and $2200 \mathrm{~mm}$ high. The size of the single-person cabin was determined to be the same as that of a single bed. The single-person cabin of the same size as that of a single bed was studied so that the single-person cabin can be used as a bed at normal times, and used for dry sauna by those who like dry sauna in their own house where they live [10]. In addition, the heating area of the single-person cabin experimental apparatus is $0.63 \mathrm{~m}^{2}$, and an experimental study and 3D simulation was conducted to implement well-being heating beneficial to health by supplying radiant heat from hot water by embedding hot water panels in the bed and walls and configuring the hot water panels so that hot water is circulated in them. The experimental study and 3D simulations were carried out so that a residential life with a bed and the loess dry sauna room can be implemented at the same time by constructing a loess bed and loess walls. The bed and walls were constructed with loess ondol panels to implement loess radiant heat room heating thereby developing a well-being heating technology beneficial to health. In winter, the temperature of the hot water circulating in the ondol panels of the bed and walls can be raised and adjusted so that loess radiant heat dry sauna can be enjoyed in the bed space depending on the resident's taste. In spring and autumn, the ceiling of the single-person cabin with bed that can be also used as a loess dry sauna room can be placed at the height of the ceiling of the room, the wall can be placed in close contact with the wall of the room, and the door can be opened or easily detached depending on the resident's taste so that the single- 
person cabin has the same feeling and sense as a normal bed and can be used as a bed. Depending on the resident's taste, even in spring and autumn, the door can be closed, and the loess radiant heat dry sauna room can be operated whenever the resident wants to enjoy loess radiant heat dry sauna. In addition, the existing heating of a single-person cabin heated the entire room (10 to $13 \mathrm{~m}^{2}$ ), but in this study, a technology that can only heat the bed space $\left(0.63 \mathrm{~m}^{2}\right)$ was developed to greatly reduce the heating energy consumption rate. In this study, an experimental apparatus for a loess dry sauna room that goes beyond the dry sauna room culture and enables enjoying dry sauna in the house where the person resides was made and the characteristics of temperature distribution in the dry sauna room were studied. As a result of this study as such, well-being heating, which is comfortable and beneficial to health, was implemented because radiant heating is implemented without movement or circulation of air unlike forced convection heating in which air is circulated by force with an air conditioner. A hot water boiler and a hot water pump were constructed to configure the experimental apparatus so that hot water is supplied to the hot water tubes embedded in the walls of the loess dry sauna room for heating.

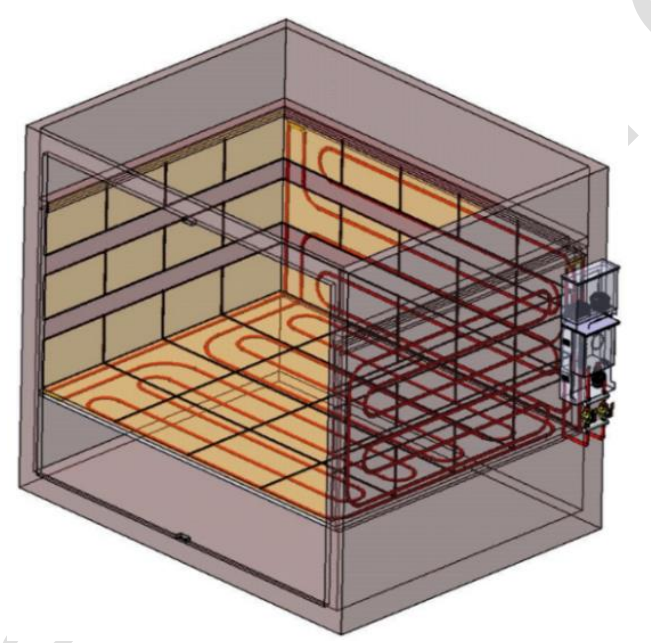

Figure 1. 3D schematic diagram of the single-person cabin experimental apparatus

[Figure 2] shows a wall-mounted electric hot water boiler for supplying the thermal energy of hot water to the single-person cabin. As shown in Fig. 2, an electric boiler for supplying hot water heat to the hot water panels of a single-person cabin was installed to conduct an experimental study. The noise of the electric boiler for hot water heat supply was limited to $37.5 \mathrm{~dB}$, so that there was no sleep disturbance due to noise when a person is sleeping in the single-person cabin at night. Since an indoor wall-mounted electric boiler and the technology were developed as such, the energy loss could be reduced by $5 \%$ compared to the existing technology for installing the electric boiler outdoors when considering the heat dissipation loss and the loss of heat in the pipe.

\section{Results}

[Figure 3] [Figure 6] shows the results of simulations of the surface temperatures of the wall and floor inside the single-person cabin, and the distributions of air temperatures and air flow velocities in the space inside the single-person cabin. The size of the single-person cabin is 2,000mm wide, $1,050 \mathrm{~mm}$ long, and 2,200mm high. As shown in Fig. 3, the simulations 
were carried out at a temperature of $70^{\circ} \mathrm{C}$ of the hot water flowing into the inlets of the hot water panels embedded in the walls and floor inside the single-person cabin. In addition, the simulations were carried out under the conditions of a flow rate of hot water of $3 \mathrm{~L} / \mathrm{min}$ and an outdoor temperature of $32^{\circ} \mathrm{C}$. ANSYS FLUENT R19 was used as the analysis software. The natural convection heat transfer inside the single-person cabin was simulated with gravity and incompressible ideal gas air. From the results of simulation of the temperature distribution of the air inside the single-person cabin in Fig. 4 Fig. 6, the average temperature of the air inside the single-person cabin was found to be $26.17^{\circ} \mathrm{C}$, the air temperature at a height of $300 \mathrm{~mm}$ from the base of the single-person cabin was found to be $26.57^{\circ} \mathrm{C}$ and the air temperature at a height of $1,000 \mathrm{~mm}$ from the base of the single-person cabin was found to be $26.29^{\circ} \mathrm{C}$. From the results of simulation of the air temperature distribution, the air temperature distribution resulting from to radiant heat transfer inside the single-person cabin was found to be uniform and this is considered to be well-being temperature distribution beneficial to health. In addition, in this study, the air temperature distribution measured in the experimental study and the temperature distribution value shown in the simulation results were in good agreement. Fig. 10 shows the distribution of air flow velocities in the central cross-section of the single-person cabin. The results of simulation of the air flow velocity distribution show $0.05 \sim 0.015 \mathrm{~m} / \mathrm{s}$. From the results of simulations in this study, the air flow rate was found to be much lower than that of heating by forced convective heat transfer, which is the conventional heating method. Therefore, from the results of simulation in this study, it was verified that heating is achieved by radiant heat transfer, which is beneficial to health.

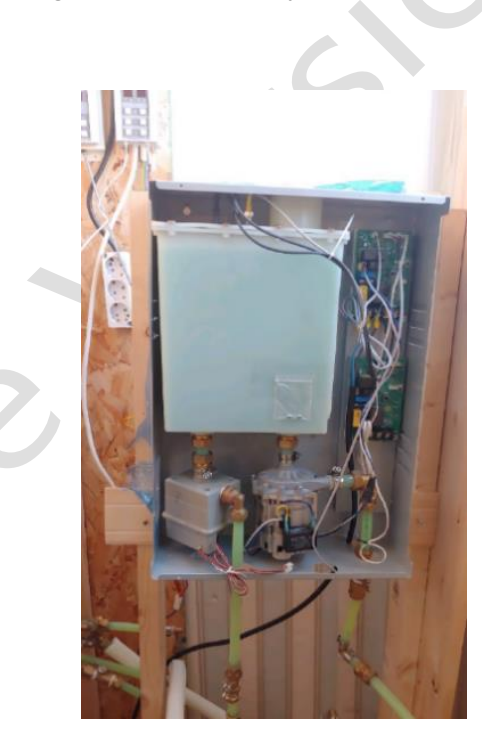

Figure 2. Wall-mounted electric hot water boiler for supplying hot water heat to single-person cabin

\section{Conclusions}

In this study, simulations were conducted on the heating heat transfer performance of a single-person cabin, and the following results were derived.

In addition, in this study, the air temperature distribution measured in the experimental study and the temperature distribution value shown in the simulation results were in good agreement.

The air flow velocity was shown to be much lower than that of heating by forced convection heat transfer, which is the existing heating method. Therefore, from the simulation 
results of this study, it was verified that heating is achieved by radiant heat transfer, which is beneficial to health.
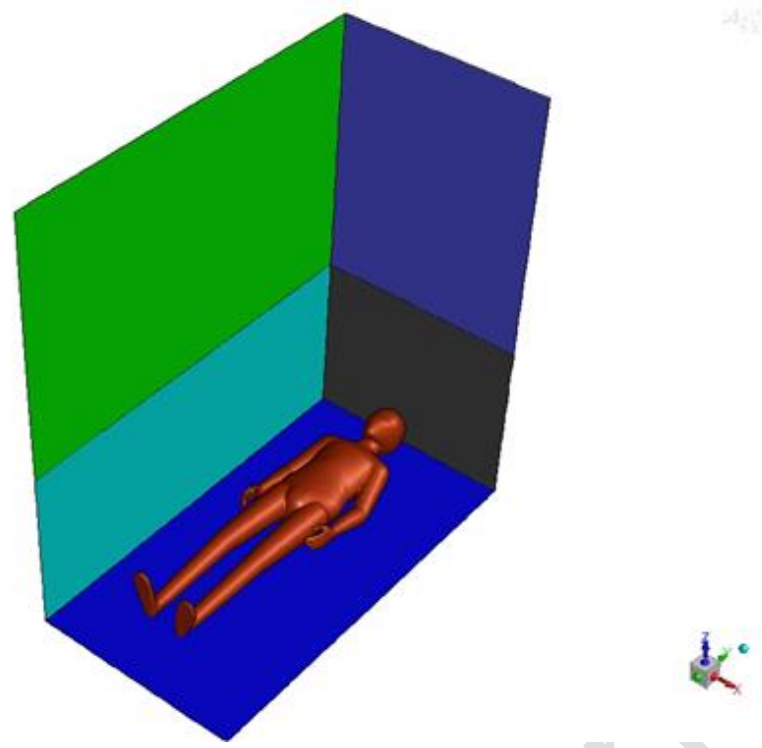

Figure 3. Shapes of simulations of surface temperatures of the walls and floor inside the single-person cabin, internal air temperature distribution and air flow velocity distribution
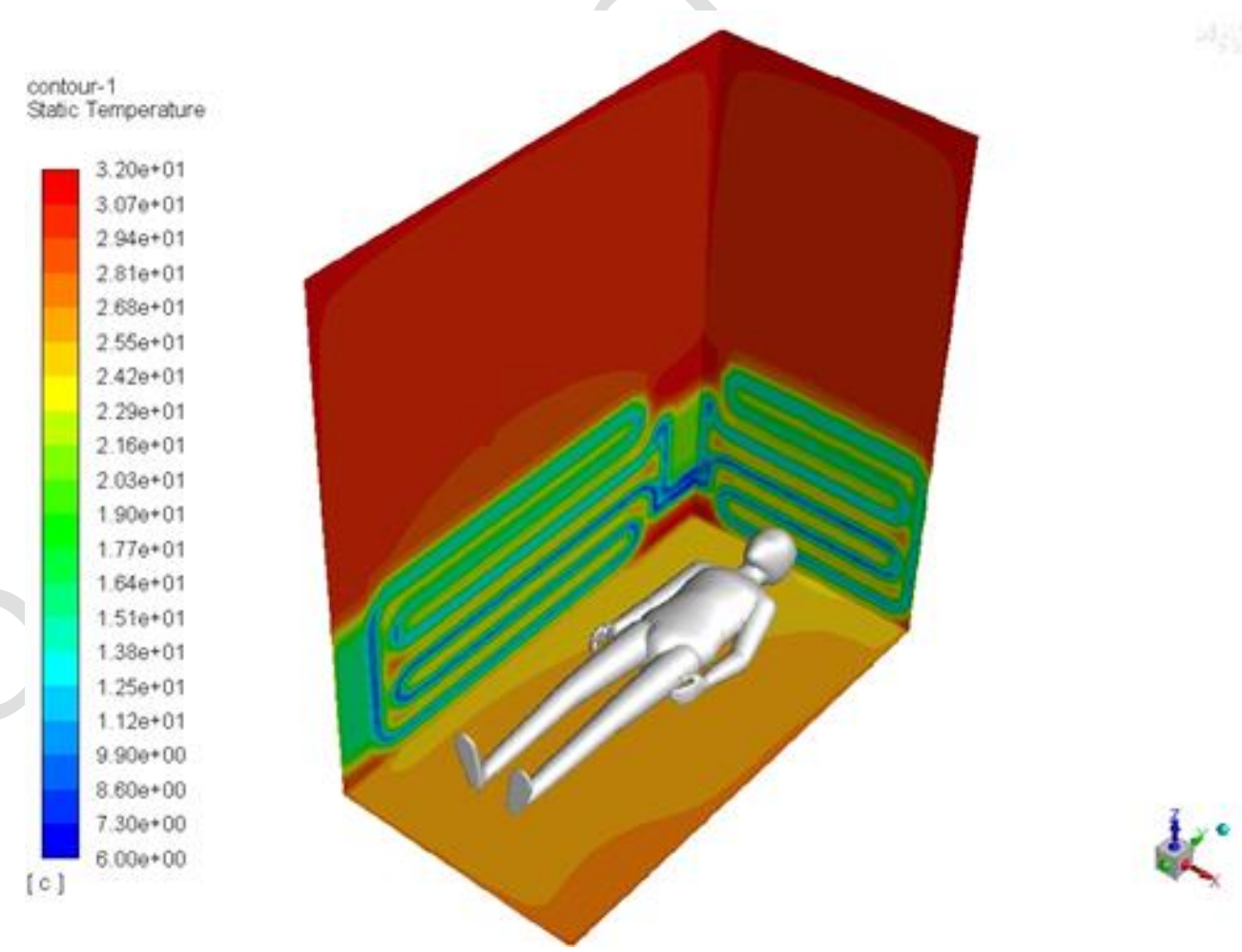

Figure 4. Distribution of temperatures of the surface of the bed in the single-person cabin 

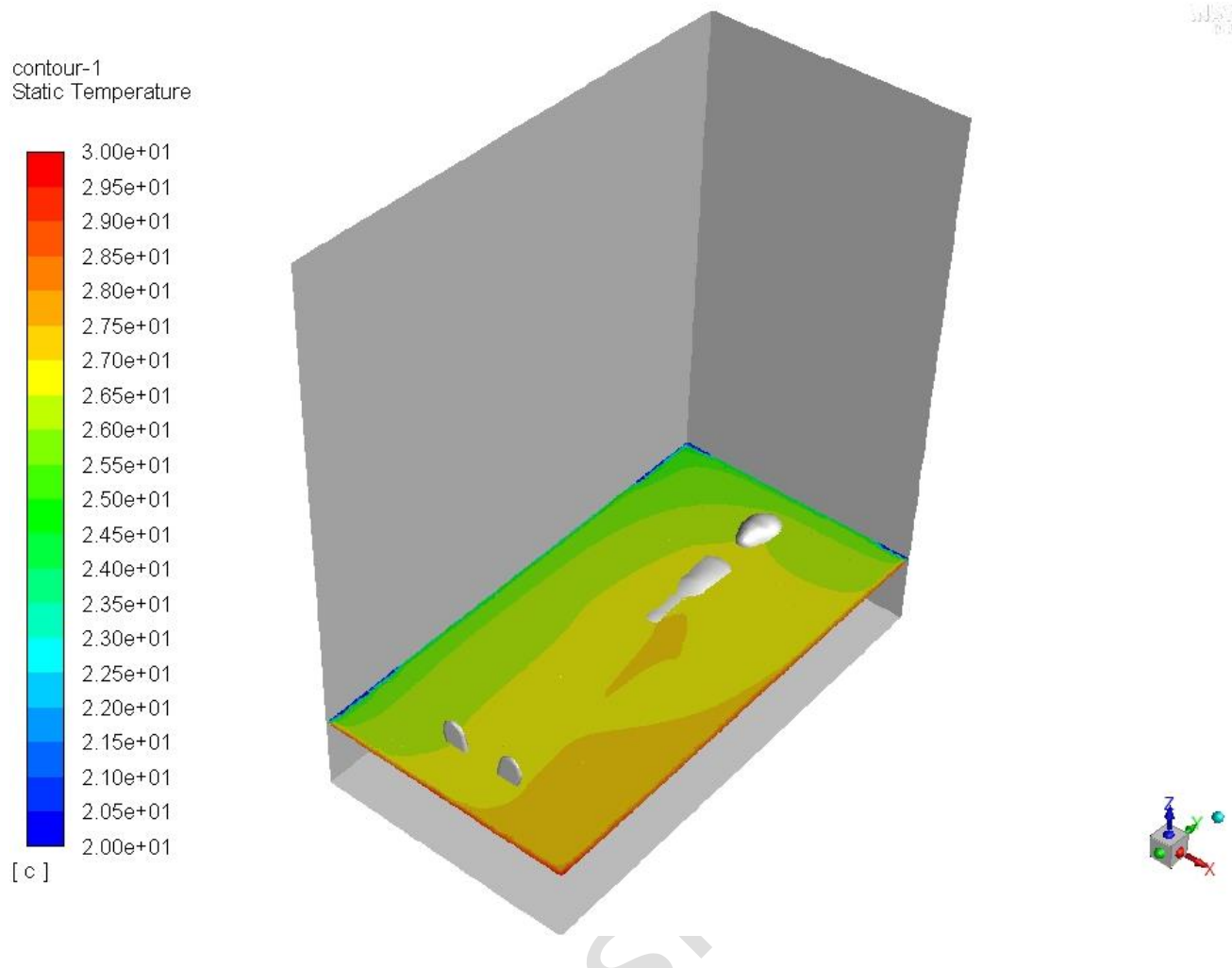

Figure 5. Distribution of temperatures on the surface of the bed at a height of $300 \mathrm{~mm}$ from the base of the single-person cabin
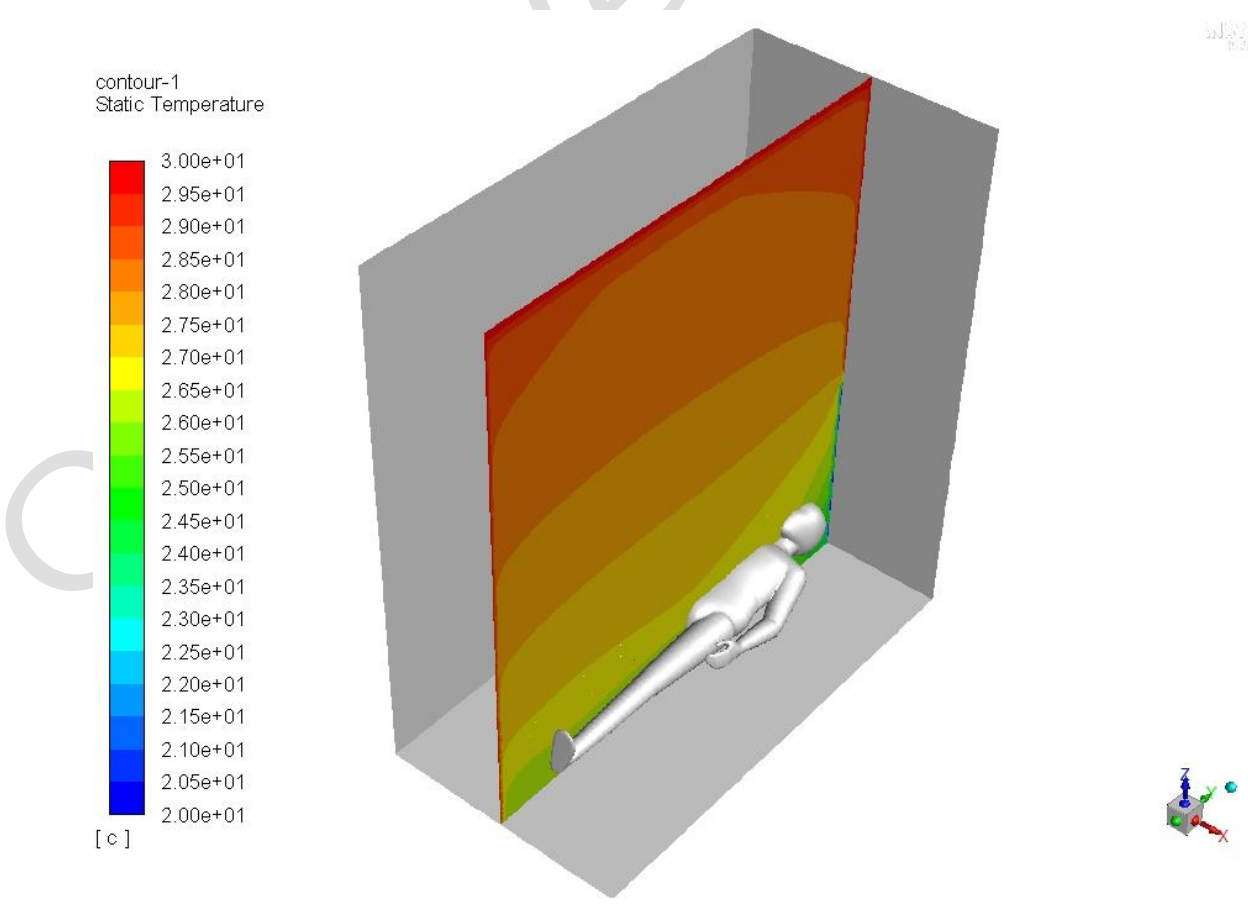

Figure 6. Distribution of air temperatures on the central cross-section inside the single-person cabin 


\title{
References
}

[1] J. Y. Kim, Y. S. Kim, H. J. Han, and J. C. Jeng, "Effect of Low temperature operation on the lifetime of district heating networks," The Korean Society of Mechanical Engineers, pp. 19-23, (2019)

[2] Y. J., Kim, M. S. Park, S. W. Cho, and J. M., Choi, “A experimental study for the surface convection heat transfer rate of the outer wall in building," Proceeding of SAREK, pp. 585-588, (2012)

[3] M. Steeman, A. Janssens, H. J.Steeman, M. Van Belleghem, and M. De Paepe, "On coupling id nonisothermal heat and mass transfer in porous materials with a multizone energy simulation model, building and environment," Building and Environment, vol.45, no.4, pp.865-877, (2010)

[4] N. Mendes, F. C. Winkelmann, R. Lamberrts, and P. C. Philippi, "Moisture Effects on Conduction Loads," Energy and Buildings, vol.35, no.7, pp.631-644

[5] J. Woods, J. Winkler, and D. Christensen, "Evaluation of the Effective Moisture Penetration Depth Model for Estimating Moisture Buffering in Buildings,” NREL technical Report, NREL/TP-5500-57441, (2013)

[6] R. M. Barbosa, and N. Mendes, "Combined Simulation of Central HVAC Systems with a whole-building Hygrothermal Model,” Energy and Buildings, vol.40, no.3, pp.276-288, (2008)

[7] F. Cappellletti, A. Gasparella, P. Romagnoni, and P. Baggio, "Analysis of the influence of installation thermal bridges on windows performance: The case of clay block walls," Journal of Energy and Buildings, vol.43, no.6, pp.1435-1442, (2011)

[8] “The government's standard assessment procedure for energy rating of dwellings," Edition, (2016)

[9] C. I. Park, and R. H. Kim, "A Study for Energy Consumption Efficiency Test Method of Domestic Gas Boiler," Proceeding of The Korea Society for Energy Engineering, pp.157, (2012)

[10] The U. S. DOE, Energy Plus Engineering Reference, The Reference to Energy Plus Calculation, (2011)

\section{Authors}

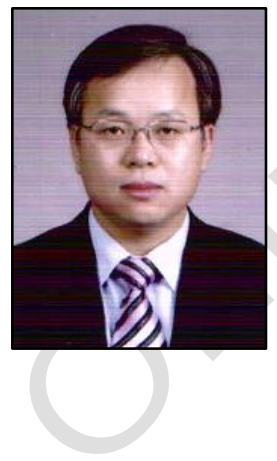

\author{
Dr. Dong-Hyun Cho \\ Professor \\ Daejin University, South Korea
}


This page is empty by intention. 